\title{
EFEKTIVITAS EKSTRAK ETANOL DAUN BAYAM MERAH (Amaranthus tricolor) SEBAGAI DIURETIK PADA TIKUS PUTIH JANTAN GALUR WISTAR (Rattus novergicus)
}

\section{EFFECTIVENESS OF LEAF EXTRACT ETHANOL RED SPINACH (Amaranthus tricolor) DIURETICS AS ON WHITE WISTAR MALE RAT (Rattus novergicus)}

\author{
I GUSTI AGUNG AYU KUSUMA WARDANI ${ }^{1 \bullet}$, KETUT AGUS ADRIANTA ${ }^{1}$ \\ ${ }^{1}$ Akademi Farmasi Saraswati Denpasar, Jalan Kamboja No. 11A, Denpasar, Bali
}

\begin{abstract}
Abstrak: Diuretik adalah zat-zat yang dapat memperbanyak pengeluaran kemih melalui kerja langsung terhadap ginjal. Salah satu tumbuhan yang secara empirik berkhasiat sebagai diuretik yaitu daun bayam merah (Amaranthus tricolor). Tujuan penelitian ini untuk mengetahui efek diuretik ekstrak etanol daun bayam merah pada tikus putih jantan galur wistar. Hewan uji sebanyak 24 ekor tikus jantan galur wistar dibagi menjadi 4 kelompok dipuasakan selama 5-6 jam, kelompok I kontrol negatif diberi suspensi CMC Na 0,5\%, kelompok II kontrol positif diberi suspensi furosemid dosis $0,72 \mathrm{mg} / 200 \mathrm{gBB}$, kelompok III diberi suspensi ekstrak $25 \%$ dan kelompok IV suspensi ekstrak 40\%. Ekstrak etanol diberikan pada hewan uji secara per oral dengan volume pemberian 2,5 ml. Hewan uji dimasukkan dalam metabolic cage, diberi $5 \mathrm{ml}$ air minum secara per oral tiap 3 jam. Data dianalisis dengan uji Kruskal-Wallis, apabila terdapat perbedaan yang bermakna dilanjutkan uji Mann-Whitney dengan taraf kepercayaan 95\%. Analisis statistik menunjukkan terdapat perbedaan signifikan $(\mathrm{p}<0,05)$ antara kontrol negatif dan kontrol positif serta konsentrasi ekstrak. Berdasarkan hasil tersebut dapat disimpulkan ekstrak etanol daun bayam merah memiliki efek diuretik pada tikus putih jantan galur wistar.
\end{abstract}

Kata kunci: daun bayam merah, diuretik, ekstrak

Abstract: Diuretics are substances that can reproduce expenditure urine (diuresis) by working directly on the kidneys. One plant that is empirically efficacious as a diuretic which leaves red amaranth (Amaranthus tricolor). The purpose of this study to know the diuretic effect of ethanol extract of spinach leaves red on white male rats wistar strain. The test animals were 24 male rats wistar strain were divided into 4 groups fasted for 5-6 hours, negative control group I were given a suspension $\mathrm{CMC} \mathrm{Na} 0,5 \%$, group II positive control suspension was given furosemide dose of $0,72 \mathrm{mg} / 200 \mathrm{gBB}$, group III was given suspension extract $25 \%$ and group IV suspension extract $40 \%$. The ethanol extract was given to the test animals orally with administration of $2.5 \mathrm{ml}$ volume. Animal trials included in the metabolic cage, was given $5 \mathrm{ml}$ of water orally every 3 hours. Data were analyzed with the Kruskal-Wallis test, if there is a significant difference continued Mann-Whitney test with a level of $95 \%$. Statistical analysis showed a significant difference $(p<0.05)$ between the negative control and a positive control and the concentration of the extract. Based on these results we can conclude ethanol extract of red spinach leaves have a diuretic effect on male rats wistar strain.

Keywords: diuretics, extract, red spinach leaves

\section{PENDAHULUAN}

Indonesia memiliki keanekaragaman hayati terbesar kedua setelah Brazil. Sekitar 30.000 jenis tumbuhan obat dimiliki Indonesia. Akan tetapi, sumber daya alam tersebut belum dimanfaatkan secara optimal bagi kepentingan masyarakat. Baru sekitar 1200 spesies tumbuhan obat yang dimanfaatkan dan diteliti sebagai obat tradisional. Kecenderungan masyarakat dunia untuk kembali ke alam membawa perubahan pada pola pengobatan ke obat-obatan yang terbuat dari bahan alami. Berdasarkan data WHO, sekitar $80 \%$ penduduk dunia dalam perawatan kesehatannya memanfaatkan obat tradisional yang berasal dari ekstrak tumbuhan (Jhonhref, 2007). Banyak tanaman yang dimanfaatkan secara empiris sebagai obat tradisional, salah satunya adalah bayam merah.

Di masyarakat daun bayam merah biasanya digunakan secara turun-temurun untuk melancarkan ASI, penurun tekanan darah, penambah darah (Trihardjana, 2007) serta dapat digunakan sebagai antibakteri (Kusmiati, 2014). Berdasarkan penelitian yang telah dilakukan oleh Trihardjana (2007) diketahui bahwa ekstrak daun

• email korespondensi: kusuma.wardhani21@yahoo.com 
bayam duri (Amaranthus spinosus L) memiliki efek diuretik pada tikus putih jantan.

Tanaman obat yang bersifat diuretik adalah tanaman obat yang salah satu sifatnya dapat meluruhkan air seni (diuretik) (Permadi, 2006). Menjaga kelancaran pengeluaran air seni atau air kencing adalah tindakan yang benar dan dianjurkan dalam dunia kesehatan. Sebagian besar air seni merupakan zat yang tidak berguna sehingga secara otomatis dibuang oleh tubuh. Apabila pengeluaran air seni terhambat maka akan menimbulkan banyak masalah di dalam tubuh, sebagai contoh akibat pengeluaran air seni yang tidak lancar adalah edema dan hipertensi (Permadi, 2006).

Masyarakat di Kota Denpasar menggunakan daun bayam merah secara turuntemurun sebagai peluruh air seni. Berdasarkan penelitian sebelumnya oleh Trihardjana (2007) tentang efek diuretik pada daun bayam duri, maka perlu dilakukan penelitian untuk mengetahui efektivitas daun bayam merah sebagai diuretik pada tikus putih jantan galur wistar.

\section{BAHAN DAN METODE}

Rancangan Penelitian. Jenis penelitian yang dilakukan adalah penelitian eksperimental Randomized Control Group Posttest Only Design. Hewan uji sebanyak 24 ekor tikus jantan galur wistar dibagi menjadi 4 kelompok yang terdiri dari 1 kelompok kontrol positif (diberi suspensi furosemide), 1 kelompok kontrol negatif (diberi suspensi CMC Na 0,5\%) dan 2 kelompok uji (diberi suspensi ekstrak etanol daun bayam merah dengan konsentrasi $25 \%$ dan $40 \%$ ).

Bahan. Bahan yang digunakan dalam penelitian ini adalah simplisia daun bayam merah yang berasal dari Kecamatan Denpasar Utara-Bali, etanol 80\%, aquadest, $\mathrm{CMC} \mathrm{Na}$ (natrium carboxymethyl cellulose) $0,5 \%$, furosemide $40 \mathrm{mg}$, $\mathrm{FeCl} 31 \%, \mathrm{HCl} 2 \mathrm{~N}$ pekat, bubuk $\mathrm{Mg}$, kloroform, amoniak, asam sulfat $2 \mathrm{~N}$, asam asetat glasial, pereaksi Mayer, pereaksi Dragendorff, pereaksi Wagner.

Metode. Daun bayam merah segar dipanen dan dibuat menjadi serbuk simplisia, selanjutnya diekstraksi dengan metode maserasi menggunakan pelarut etanol $80 \%$. Filtrat etanol daun bayam merah selanjutnya dievaporasi sehingga diperoleh ekstrak kental. Ekstrak kental daun bayam merah ini selanjutnya akan digunakan untuk menguji efek diuretik pada tikus yang telah melalui fase adaptasi.

Pembuatan Suspensi CMC Na 0,5\%. Sebanyak $0,5 \mathrm{~g}$ CMC Na dilarutkan dalam mortar yang berisi $10 \mathrm{~mL}$ aquadest yang telah dipanaskan, lalu dicampur dan digerus sampai homogen. Selanjutnya, suspensi CMC Na dipindahkan ke dalam labu ukur $100 \mathrm{~mL}$. Volumenya dicukupkan dengan aquadest hingga $100 \mathrm{~mL}$. Suspensi CMC $\mathrm{Na}$ 0,5\% digunakan sebagai kontrol negatif.

Pembuatan Suspensi Furosemide. Menurut Drug Information Handbook, dosis penggunaan furosemide pada manusia dewasa adalah 20-80 $\mathrm{mg}$. Pada penelitian ini digunakan dosis $40 \mathrm{mg}$ dengan faktor konversi dari manusia $(70 \mathrm{~kg}) \mathrm{ke}$ tikus dengan berat $200 \mathrm{~g}$ ialah 0,018 , maka dosis furosemide untuk tikus adalah $0,72 \mathrm{mg} / 200 \mathrm{gBB}$ yang dilarutkan dengan suspensi CMC Na 0,5\%. Suspensi furosemid digunakan sebagai kontrol positif

Ekstrak etanol daun bayam merah. Ekstrak etanol daun bayam merah dibuat menjadi 2 konsentrasi yaitu $25 \%$ dan $40 \%$ yang dilarutkan dalam suspensi CMC Na 0,5\%. Masing-masing tikus akan diberikan 2,5 $\mathrm{ml}$ suspensi ekstrak etanol.

Pengukuran Volume Urin. Setelah diberi perlakuan, hewan uji dimasukkan ke dalam metabolic cage untuk ditampung urinnya. Pengukuran volume urin dilakukan pada menit ke 30 dan jam ke 1, 2, 3, 4, 5, 6, 7 dan 8 . Volume urin yang diukur adalah volume urin tiap waktu pengamatan dan volume urin kumulatif. Air minum diberikan setiap 3 jam dikontrol sebanyak $5 \mathrm{ml}$ untuk tiap hewan uji. Selama perlakuan dalam metabolic cage hewan uji tidak diberi makan. Efektivitas ekstrak etanol daun bayam merah dilakukan selama 1 hari dengan pengulangan sebanyak 3 .

Analisa Data. Data yang diperoleh dianalisis dengan menggunakan program statistika metode SPSS ver.16. Kemudian data diuji distribusi normalnya dengan uji Saphiro-Wilk dan keseragaman varian diuji dengan uji Levene menggunakan taraf kepercayaan 95\%. Data yang diperoleh tidak terdistribusi normal, maka dilakukan uji Kruskal-Wallis dan dilanjutkan dengan uji Mann-Whitney. 


\section{HASIL DAN PEMBAHASAN}

Data volume urin diukur pada menit ke-30, jam ke$1,2,3,4,5,6,7$ dan 8 . Data yang terkumpul merupakan data volume urin tiap waktu $(\mathrm{ml})$, dari data tersebut dapat dihitung volume urin kumulatif. Rata-rata volume urin tiap waktu pengamatan dapat dilihat pada tabel 1 di bawah ini.

\section{Tabel 1. Data Rata-Rata Volume Urin Tiap Waktu Pengamatan}

\begin{tabular}{|l|c|c|c|c|c|c|c|c|c|}
\hline \multirow{2}{*}{ Kelompok } & \multicolumn{9}{|c|}{ Volume Urin Tiap Menit dan Jam ke (ml) } \\
\cline { 2 - 10 } & $\mathbf{3 0}$ menit & $\mathbf{1 ~ j a m}$ & $\mathbf{2 ~ j a m}$ & $\mathbf{3 ~ j a m}$ & $\mathbf{4 ~ j a m}$ & $\mathbf{5}$ jam & $\mathbf{6}$ jam & $\mathbf{7}$ jam & $\mathbf{8}$ jam \\
\hline K I & $0,00 \pm 0,00$ & $0,00 \pm 0,00$ & $0,00 \pm 0,00$ & $0,00 \pm 0,00$ & $0,25 \pm 0,40$ & $0,37 \pm 0,39$ & $0,88 \pm 0,81$ & $1,13 \pm 1,20$ & $1,82 \pm 1,33$ \\
\hline K II & $0.02 \pm 0,04$ & $1.03 \pm 1,18$ & $0.27 \pm 0,45$ & $0.00 \pm 0,00$ & $0.22 \pm 0,40$ & $1.27 \pm 0,84$ & $0.27 \pm 0,42$ & $1.85 \pm 1,05$ & $1.50 \pm 0,82$ \\
\hline K III & $0.07 \pm 0,16$ & $1.18 \pm 1,28$ & $0.40 \pm 0,46$ & $0.20 \pm 0,40$ & $0.88 \pm 1,48$ & $1.23 \pm 0,95$ & $0.77 \pm 0,95$ & $1.52 \pm 1,36$ & $1.00 \pm 0,71$ \\
\hline K IV & $0.02 \pm 0,04$ & $1.55 \pm 1,26$ & $1.08 \pm 1,26$ & $0.22 \pm 0,37$ & $1.78 \pm 1,17$ & $0.38 \pm 0,89$ & $1.20 \pm 1,18$ & $0.73 \pm 0,82$ & $1.25 \pm 1,08$ \\
\hline
\end{tabular}

\section{Keterangan:}

Kelompok I

Kelompok II

Kelompok III

Kelompok IV
Kelompok kontrol negatif (CMC Na 0,5\%)

: Kelompok kontrol positif (furosemide)

Kelompok perlakuan ekstrak $25 \%$

Kelompok perlakuan ekstrak $40 \%$
Untuk melihat adanya perubahan volume urin secara keseluruhan selama waktu pengamatan maka dapat dilihat pada data volume urin kumulatif pada tabel 2 .

Tabel 2. Data Volume Urin Kumulatif Tiap Waktu Pengamatan $(\mathrm{ml})$ pada Masing-Masing Kelompok Perlakuan

\begin{tabular}{|c|c|c|c|c|c|c|c|c|c|}
\hline \multirow{2}{*}{ Kelompok } & \multicolumn{10}{|c|}{ Oolume Urin Tiap Menit dan Jam ke (ml) } \\
\cline { 2 - 10 } & $\begin{array}{c}\mathbf{3 0} \\
\text { menit }\end{array}$ & $\begin{array}{c}\mathbf{1} \\
\text { jam }\end{array}$ & $\begin{array}{c}\mathbf{2} \\
\text { jam }\end{array}$ & $\begin{array}{c}\mathbf{3} \\
\text { jam }\end{array}$ & $\begin{array}{c}\mathbf{4} \\
\text { jam }\end{array}$ & $\begin{array}{c}\mathbf{5} \\
\text { jam }\end{array}$ & $\begin{array}{c}\mathbf{6} \\
\text { jam }\end{array}$ & $\begin{array}{c}7 \\
\text { jam }\end{array}$ & $\begin{array}{c}\mathbf{8} \\
\text { jam }\end{array}$ \\
\hline K I & 0.00 & 0.00 & 0.00 & 0.00 & 0.25 & 0.62 & 1.50 & 2.63 & 4.45 \\
\hline K II & 0.02 & 1.05 & 1.32 & 1.32 & 1.59 & 2.85 & 3.11 & 4.96 & 6.46 \\
\hline K III & 0.06 & 1.24 & 1.64 & 1.84 & 2.72 & 3.95 & 4.72 & 6.29 & 7.29 \\
\hline K IV & 0.02 & 1.57 & 2.65 & 2.92 & 4.70 & 5.08 & 6.28 & 7.01 & 8.26 \\
\hline
\end{tabular}

Untuk mempermudah pengamatan, hasil volume urin kumulatif tiap waktu pengamatan dapat dilihat pada gambar I.

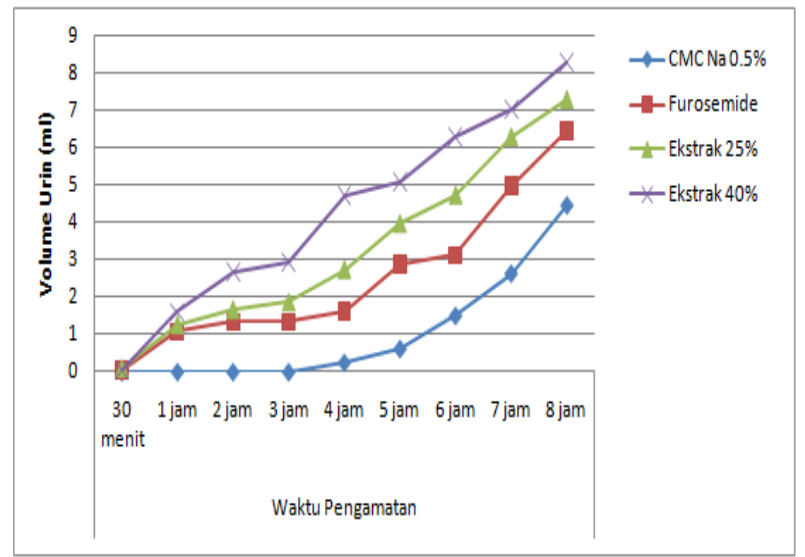

\section{Gambar 1. Grafik Volume Urin Kumulatif tiap Waktu Pengamatan}

Data volume urin pada masing-masing kelompok diuji normalitasnya menggunakan uji Saphiro-Wilk. Pada uji normalitas diperoleh hasil sebaran data tidak terdistribusi normal. Kemudian dilanjutkan dengan uji homogenitas, menunjukkan nilai sig $=0.277(\mathrm{p}>0.05)$, yang artinya data bervariasi homogen. Untuk melihat apakah ada perbedaan yang signifikan dari empat kelompok maka dilakukan uji Kruskal-Wallis.

Hasil pengujian Kruskal-Wallis menunjukan nilai sig $=0.016$ ( $\mathrm{sig}<0.05)$, yang menunjukan bahwa ada perbedaan yang signifikan dari empat kelompok. Selanjutnya dilakukan pengujian dengan uji Mann-Whitney (Tabel 3).

Tabel 3. Hasil Uji Mann-Whitney

\begin{tabular}{|c|l|l|l|}
\hline \multicolumn{2}{|c|}{ Kelompok Perbandingan } & \multicolumn{1}{|c|}{$\mathrm{P}$} & \multicolumn{1}{c|}{ Keterangan } \\
\hline \multirow{3}{*}{$\begin{array}{c}\text { K I } \\
\text { CMC Na 0.5\% }\end{array}$} & K II & 0.046 & Ada perbedaan \\
\cline { 2 - 4 } & K III & 0.019 & Ada perbedaan \\
\cline { 2 - 4 } & K IV & 0.005 & Ada perbedaan \\
\hline \multirow{3}{*}{$\begin{array}{c}\text { K II } \\
\text { Furosemide }\end{array}$} & K I & 0.046 & Ada perbedaan \\
\cline { 2 - 4 } & K III & 0.453 & Tidak ada perbedaan \\
\cline { 2 - 4 } Ekstrak 25\% & K IV & 0.157 & Tidak ada perbedaan \\
\hline \multirow{2}{*}{$\begin{array}{c}\text { K III } \\
\text { K IV }\end{array}$} & K I & 0.019 & Ada perbedaan \\
\cline { 2 - 4 } & K IV & 0.453 & Tidak ada perbedaan \\
\cline { 2 - 4 } & K I & 0.508 & Tidak ada perbedaan \\
\cline { 2 - 4 } & K II & 0.005 & Ada perbedaan \\
\cline { 2 - 4 } & K III & 0.157 & Tidak ada perbedaan \\
\hline
\end{tabular}

Hasil pengujian Mann-Whitney menunjukan bahwa pada kelompok suspensi CMC $\mathrm{Na}$ 0,5\% (kontrol negatif) menunjukkan perbedaan yang signifikan dengan suspensi furosemide (kontrol positif) dan suspensi ekstrak etanol daun bayam merah konsentrasi $25 \%$ dan $40 \%$. Hal ini disebabkan karena di dalam suspensi CMC Na $0,5 \%$ tidak terkandung zat-zat yang dapat meningkatkan volume urin (diuretik).

Selanjutnya, kelompok suspensi furosemide menunjukkan perbedaan yang signifikan dengan kelompok suspensi CMC $\mathrm{Na}$ $0,5 \%$, dan tidak menunjukkan perbedaan dengan kelompok perlakuan suspensi ekstrak etanol daun bayam merah. Hal ini berarti ekstrak etanol daun 
bayam merah mempunyai efek yang tidak jauh berbeda (sama) dengan furosemide dalam mengeksresikan urin pada tikus.

Pada pemberian konsentrasi ekstrak 25\% dan $40 \%$ tidak menunjukkan perbedaan yang bermakna, hal ini berarti ekstrak konsentrasi $25 \%$ mempunyai efek yang tidak jauh berbeda (sama) dengan konsentrasi $40 \%$ dalam mengekskresikan urin. Efek diuretik yang ditimbulkan pada ekstrak disebabkan adanya kandungan flavonoid yang berperan dalam meningkatkan volume urin (diuretik). Mekanisme kerja flavonoid sebagai diuretik sebagaimana yang disebutkan Khabibah (2012), yaitu dengan menghambat reabsorpsi $\mathrm{Na}+$, $\mathrm{K}+$ dan Cl- sehingga terjadi peningkatan elektrolit di tubulus dan terjadilah diuresis. Selain itu penelitian lain juga menyatakan bahwa efek diuretik dapat dihasilkan dari stimulasi aliran darah regional atau penghambatan vasopressin atau dengan melalui penghambatan reabsorpsi tubuler air dan anion (Chandra, 2011).

\section{SIMPULAN}

Dari penelitian yang telah dilakukan dapat disimpulkan bahwa ekstrak etanol daun bayam merah konsentrasi 25\% memiliki efek diuretik terhadap tikus putih jantan galur wistar (Rattus norvegicus).

\section{DAFTAR PUSTAKA}

American Society for Hospital-System Pharmacist. 2008, AHFS Drug Information Handbook, ASHP Inc., Bethesda MD, USA.
Chandra (2011) dalam Isania, dkk (2014). Aktivitas Diuretik Dan Skrining Fitokimia Ekstrak Etanol Biji Pepaya (Carica Papaya L.) Pada Tikus Putih Jantan Galur Wistar (Rattus Norvegicus). Fakultas Farmasi FMIPA UNSRAT Manado.

Jhonhref. 2007, Tanaman Obat Asli Milik Masyarakat Bangsa dan Negara. http://jhonhref.wordpress.com/2007/07/017/t anaman-obat-milikmasyarakat-bangsa-dannegara.ri-2/98k, (diakses pada tanggal 25 Agustus 2016).

Khabibah, N. 2011. Uji Efek Diuretik Ekstrak Buncis (Phaseolus Vulgaris L) Pada Tikus Putih Jantan Galur Wistar [Skripsi] STIKES Ngudi Waluyo, Ungaran.

Kusmiati, Tiah, R., Ayu, A. P., 2014, 'Pengujian Ekstrak Aseton Daun Bayam (Amaranthus sp) sebagai Senyawa ANtiradikal DPPH, antibakteri, dan Identifikasi Senyawa Aktif dengan $K G S M^{\prime}$, Seminar Nasional Biologi, Jakarta, Vol. 11 No. 1

Permadi, A., 2006, Tanaman Obat Pelancar Air Seni, 5-8, Penebar Swadaya, Jakarta.

Trihardjana, 2007, Kajian Potensi Diuretika Dari Beberapa Jenis Tanaman Di Sekitar Rumah. Jurdik Biologi Fakultas Matematika dan Ilmu Pengetahuan Alam Universitas Negeri Yogyakarta, Yogyakarta. 